\title{
A Convergência Turco-Brasileira na Declaração de Teerã
}

\section{The Turkish-Brazilian Convergence in the Tehran \\ Declaration}

\section{ANDRÉ LUIZ REIS DA SILVA ${ }^{1}$ \\ RICARDO FAGUNDES LEÃES ${ }^{2}$}

Resumo: A Declaração de Teerã de maio de 2010 foi uma iniciativa turcobrasileira que visou à solução da questão nuclear iraniana. Após sucessivos fracassos, a comunidade internacional, capitaneada pelo P5 + 1 (Estados Unidos, China, Rússia, Reino Unido, França e Alemanha), surpreendeu-se com o sucesso dessa empreitada, mas não aproveitou seus resultados, encetando uma nova rodada de sanções internacionais ao Irã, a fim de debilitar ainda mais o regime islâmico. Neste artigo, partiu-se do entendimento de que a aproximação entre Brasil e Turquia se deu por diversas razões, as quais tinham origens de ordem estrutural, situacional e conjuntural. Dessa forma, realizou-se um balanço desse processo, esmiuçando os fatores que motivaram os governos de Lula e Erdoğan a se juntar para tentar dar um fim à crise nuclear no Irã.

Palavras-chave: Declaração de Teerã, Brasil e Turquia.

Abstract: The Tehran Declaration was a Turkish-Brazilian attempt to solve the Iranian nuclear crisis. After many failures, the international community, led by the P5 + 1 (United States, China, Russia, United Kingdom, France and Germany) was shocked by the success of this enterprise, but did not seize this chance, thus beginning a new round of international sanctions on Iran, with the intent to cripple the Islamic Republic. In this article, we assume that Brazil and Turkey got close in this matter for several reasons, with structural, situational and conjunctural roots. That being said, we analyzed carefully this process, in order to explain why the Lula and the Erdoğan governments gathered to try and solve the nuclear crisis in Iran.

Keywords: The Tehran Declaration, Brazil and Turkey.

\footnotetext{
${ }^{1}$ Doutor em Ciência Política pela Universidade Federal do Rio Grande do Sul (UFRGS). Pós doutorado na School of Oriental and African Studies/ University of London. Professor dos Programas de Pós-graduação em Ciência Política e Estudos Estratégicos Internacionais da UFRGS.

2 Mestrando em Ciência Política pela Universidade Federal do Rio Grande do Sul (UFRGS). Analista Pesquisador da Fundação de Economia e Estatística (FEE))
}

Recebido em 01 de agosto de 2014 Aceito em 16 de outubro de 2014

Received on August 1, 2014 Accepted October 16, 2014

DOI: 10.12957/rmi.2014.12233 


\section{Introdução}

A questão nuclear iraniana - aqui entendida como a tentativa para conciliar o direito ao uso pacífico da energia nuclear com a garantia da não proliferação de bombas atômicas - é um tema de grande importância para os Estados Unidos e seus aliados, com implicações para a balança de poder regional e para o posicionamento de outras potências sobre a temática da pesquisa nuclear. Em 2009, o presidente norte-americano Barack Obama, tão logo tomou posse, deu início a uma nova rodada de negociações com os dirigentes iranianos, prometendo se valer da diplomacia para resolver o conflito. De fato, pela primeira vez, os EUA deixaram de exigir a paralisação completa e imediata do programa nuclear iraniano como précondição para sentarem-se à mesa de negociações, fato há muito aguardado em Teerã. Todavia, malgrado essa novidade, os norte-americanos deixaram explícito, desde o princípio, que novas sanções seriam impostas ao Irã em caso de rompimento das conversas, o que levantou dúvidas sobre a sinceridade das intenções de Washington nessa empreitada.

No início de 2010, após sucessivas tentativas fracassadas para que se chegasse a um acordo relativo ao programa nuclear iraniano, já havia uma grande expectativa sobre como seria a nova rodada de sanções ao país, uma vez que as negociações envolvendo o P5 + 1 (Estados Unidos, China, Rússia, Reino Unido, França e Alemanha) e o Irã não haviam tido o desfecho imaginado. No entanto, para surpresa da comunidade internacional, Brasil e Turquia tiveram sucesso em obter o aval iraniano em um acordo nos mesmos moldes do P5 +1 , o que causou surpresa generalizada, dada a recusa anterior de Teerã em concordar com essas exigências. A despeito do ineditismo dessa empreitada e do otimismo da Agência Internacional de
Energia Atômica (AIEA), a proposta foi terminantemente rechaçada pelos Estados Unidos, que orientou seus aliados a criticála e a manter as sanções econômicas que já estavam programadas (Vidal, 2013).

A Declaração de Teerã de maio de 2010 se tornou realidade em virtude do êxito das diplomacias brasileira e turca em compreender as particularidades da República Islâmica. Seu conteúdo está articulado em dez pontos que enfatizam o direito consagrado pelo Tratado de Não Proliferação Nuclear (TNP), o qual assegura ao Irã o direito à pesquisa, produção e uso da energia nuclear para fins pacíficos. Para garantir a lisura das intenções de Teerã, o documento previa o depósito de 1200 quilos de urânio levemente enriquecido (LEU) na Turquia, material que permaneceria como propriedade iraniana. Assim que a entrega fosse efetivada, o governo iraniano informaria o Grupo de Viena (EUA, Rússia, França e AIEA), o qual se comprometeria a devolver, em um prazo máximo de um ano, 120 quilos de combustível necessários para o Reator de Pesquisas de Teerã. Caso a cláusula não fosse obedecida, a Turquia restituiria imediatamente o LEU ao Irã (Fonteijn et alli 2010, pp. 02-03).

A aceitação iraniana do acordo proposto por brasileiros e turcos se deveu, acima de tudo, ao respeito prestado por suas delegações. Em todos os momentos, as lideranças políticas desses países fizeram questão de negociar diretamente com seus homólogos iranianos, em contraste com as autoridades ocidentais. Essa postura capturou o desinteresse iraniano em conceder a um país que estivesse em uma arrogante posição de força (Ozkan, 2011, pp. 27 - 28). Ademais, ao salvaguardar o direito de Teerã de produzir energia nuclear e ao se opor à aplicação de sanções econômicas, Brasília e 
Ancara tiveram êxito em conseguir o que o P5+1 há muito intentava. Esses países, por outro lado, não receberam bem a "Declaração de Teerã", rejeitando-a desde seu anúncio. Isso porque os Estados Unidos e seus aliados não gostaram de ver países menos destacados no cenário internacional atingirem o que eles não obtiveram. Ademais, como já estava anunciado outro ciclo de sanções ao Irã, havia um temor de que o acordo pudesse soar como um sinal de fraqueza (Parsi, 2012).

Embora as tratativas turco-brasileiras, posteriormente consubstanciadas na "Declaração de Teerã", tenham se mostrado infrutíferas, salienta-se o fato de que dois países, até então pouco relevantes na crise iraniana, tenham sido pivôs de uma ação que buscou reaproximar o Irã da sociedade internacional. Mais ainda, ressalta-se o empenho demonstrado por ambos para que se atingisse uma solução pacífica e diplomática para a questão, refutando a adoção de retaliações, sob a justificativa de que essa medida apenas faria com que Teerã se acercasse ou buscasse a obtenção de uma bomba atômica. Nesse sentido, a atuação de Brasil e Turquia nessa circunstância representa um marco para a política externa desses países, na medida em que está carregada de vários aspectos originais em sua história. Brasília, por exemplo, esmerou-se para resolver um conflito em uma região onde nunca exerceu maior influência. Já Ancara, ainda que estivesse lidando com um problema regional, inovou por ir de encontro aos interesses norte-americanos, seu tradicional aliado.

Paradoxal nesse processo, contudo, foi o fato de que a participação de turcos e brasileiros foi sugerida e apoiada pelos Estados Unidos, que imaginaram que sua presença poderia facilitar o fechamento de um acordo. Na visão norte-americana, a Turquia representava um aliado do Oriente
Médio, o que seria importante para construir uma ponte com os iranianos, que se mostravam recalcitrantes a aceitar os seus desígnios. Por outro lado, a ação do Brasil era percebida como uma maneira de atrair à mesa de negociações um Estado que, até então, ficara alheio ao tema, também a fim de dirimir as desconfianças iranianas. $\mathrm{Na}$ mesma linha, para o presidente norte-americano Barack Obama, o seu homólogo brasileiro já havia se provado uma liderança adequada no cenário mundial, capaz de se valer do diálogo e de construir consenso. Todavia, como visto, a solução aventada não foi bem vista, frustrando as expectativas dos novos atores.

Este artigo aborda os fatores que motivaram a convergência turco-brasileira em busca de uma resposta para a crise envolvendo o programa nuclear iraniano. Não se trata, portanto, de um estudo a respeito da Declaração de Teerã, tampouco de uma avaliação sobre a situação energética iraniana, mas sim de uma análise sobre os condicionantes que fizeram com que Brasil e Turquia buscassem solucionar esse dilema. Em boa medida, essa pesquisa se justifica em função da relevância do tema para as relações internacionais, por mais que a literatura, até agora, pouco tenha se debruçado sobre o assunto. Em decorrência das duras críticas que recebe o Irã - país que faz parte do "Eixo do Mal", segundo o governo norte-americano -, essa iniciativa acabou sendo admoestada por amplos setores nesses países, sobretudo os midiáticos, que culparam Lula e Erdoğan por essa investida (Pinto, 2012).

É do nosso entendimento que a Declaração de Teerã é, acima de tudo, consequência das recentes transformações da política externa brasileira e turca, visto que esses Estados têm reafirmado, nos últimos anos, seu papel como potências regionais, o que os impulsionaria a ter maior proeminência nos assuntos de fundamental importância da 
política internacional. $\mathrm{Na}$ mesma linha dessa argumentação se acrescenta o objetivo compartilhado por turcos e brasileiros para sanar as crises de uma maneira pacífica e diplomática, abdicando do uso da força para fazer seus interesses. Em termos mais específicos, observa-se que tanto Brasília quanto Ancara sempre fazem questão de assegurar o direito ao uso pacífico da energia nuclear, consagrado no artigo IV do Tratado de Não-Proliferação Nuclear (TNP). Isso não decorre apenas de um respeito ao direito internacional, mas é fruto do interesse que ambos têm em desenvolver sua capacidade nuclear. Finalmente, a vontade que têm brasileiros e turcos de alavancar investimentos no setor petrolífero iraniano não pode ser negligenciada.

Nesse estudo, lançamos mão da análise bibliográfica do objeto em questão - a política externa de Brasil e Turquia e os fatores que os motivaram a buscar uma solução para a crise iraniana. Além disso, serviram de base para a investigação os documentos governamentais e os discursos oficiais que diziam respeito à Declaração de Teerã, com a intenção de verificar como que o acordo foi apresentado pelas diplomacias turca e brasileira. Metodologicamente, procuramos assentar nossa exploração através de uma perspectiva que considera fatores de curto, médio e longo prazo, os quais perfazem, respectivamente, elementos conjunturais, situacionais e estruturais, articulando diferentes condicionamentos temporais. Em um primeiro momento, foram apreciadas brevemente as principais variações do projeto de inserção estratégica dos governos brasileiro e turco no século XXI, as quais representam causas situacionais. Após essa exposição, foram averiguados os fenômenos estruturais e conjunturais, que, em nossa visão, revelam os pontos de convergência desses países no que concerne ao Irã.

\section{O AKP e a "Teoria da Profundidade Estratégica"}

A política externa turca atravessou um período de intensas transformações a partir da vitória do Partido da Justiça e do Desenvolvimento (AKP) nas eleições gerais de 2002. Até então, era consensual entre os analistas que a diplomacia do país gravitava em torno dos objetivos norte-americanos, procurando aferir os eventuais benefícios que essa aliança poderia proporcionar. De fato, desde o final da II Guerra Mundial, quando a União Soviética já mostrava interesse na utilização do território turco para suas bases militares - o que era visto como um risco à soberania turca -, Ancara tratou de se acercar dos Estados Unidos, à procura de um protetor externo. Nesse período, os turcos mantinham uma política de low profile com seus vizinhos, evitando conflitos que colocassem sua integridade territorial em risco. Esses movimentos explicam o porquê do ingresso da Turquia na Organização do Atlântico Norte (OTAN), em 1952, bem como o reconhecimento diplomático do Estado de Israel em 1949 (Dicle 2008, p. 13).

Conquanto a inserção estratégica de Ancara tenha se alterado levemente nas décadas subsequentes, as eventuais mudanças não configuraram mais do que ajustes, jamais ocasionando qualquer ameaça ao alinhamento com os EUA. Da mesma forma, a política regional da Turquia não se robusteceu, mantendo o país com uma imagem de um perigoso outsider ocidental no Oriente Médio. Na sequência, com o desfecho da Guerra Fria e o fim da ameaça soviética, os governantes turcos sinalizaram uma participação mais assertiva em sua região, pois julgaram que o término da bipolaridade ampliava sua margem de manobra. Todavia, essas modificações se desenrolaram na ausência absoluta de sobressaltos diplomáticos, como atesta a permissão dada às Forças Armadas norte- 


\section{Mural Internacional}

americanas para utilizar o solo turco, em 1991, durante a Guerra do Golfo. Ademais, ao longo da década de 1990, a parceria militar turco-israelense atingiu seu pico em termos de venda de armamentos e treinamentos conjuntos (Kaya 2011, pp. 02 - 03).

A partir de 2002, enfim, com a ascensão do AKP, o governo turco imprimiu um novo caminho em sua política externa, sinalizando as transformações que explicam a participação do país na Declaração de Teerã. Tão logo chegou ao poder, o partido lançou mão da "Teoria da Profundidade Estratégica", do acadêmico Ahmet Davutoğlu, para balizar sua inserção internacional. Segundo o autor, que depois foi alçado à posição de Ministro das Relações Exteriores, a Turquia não era uma ponte entre o Ocidente e o Oriente, mas sim uma potência regional com capacidade para resolver pacificamente conflitos que envolvessem os Estados que lhe eram próximos. Para tanto, era fundamental uma política de "nenhum problema com os vizinhos", o que constituía uma enorme dificuldade, uma vez que os turcos tinham disputas com gregos, cipriotas, sírios, libaneses, curdos e iranianos. Com efeito, esse projeto espelhava as raízes islâmicas do AKP, que não aprovava a diplomacia levada a cabo pelos militares secularistas nas décadas anteriores (Baran et al 2008, pp. 08-10).

O elemento político-ideológico foi imprescindível para viabilizar a execução da Teoria da Profundidade Estratégica, fenômeno que se explica a partir do estudo das relações entre civis e militares na política turca. $\mathrm{Na}$ verdade, desde a proclamação da República, em 1923, o Exército se portou como o fiador do secularismo no país, impedindo, através de sucessivos golpes de Estado, a presença de partidos com origem religiosa no poder. Havia, também, uma percepção de que
Ancara estava cercada de países hostis, interessados em sua fragmentação territorial, o que colocava em perigo as conquistas seculares obtidas a partir do regime de Mustafá Kemal, o fundador da Turquia moderna. Nesse contexto, as Forças Armadas justificavam sua aliança com Estados Unidos e Israel alegando ser essa a única maneira de proteger a Turquia de confrontos militares com seus vizinhos (Balci e Kardaş 2012, pp. 103-104).

O AKP tradicionalmente rejeita essa perspectiva, hegemônica nos círculos militares. De acordo com suas lideranças, a Turquia não era um país europeu ocidentalizado que estava circundado por Estados islâmicos beligerantes. Embora não apregoasse uma reversão nos atributos seculares da República, o AKP não escondeu seu caráter muçulmano, argumentando que a religião comum aproximava os turcos de seus vizinhos. Houve, nesse ponto, uma significativa inflexão, pois o governo de Erdoğan teve muito sucesso em sua estratégia de "nenhum problema com os vizinhos", ao menos até o início da Primavera Árabe. Em 2010, Ancara encontrava-se em uma situação muito confortável, tendo mitigado as tensões regionais que permearam os períodos anteriores. Nessas circunstâncias, a sensação de insegurança se dissipara, eliminando a necessidade de uma aliança inquebrantável com Estados Unidos e Israel. Em relação a esse último, destaca-se a defesa turca dos interesses palestinos evento sui generis na história desse confronto -, cristalizada nas severas críticas de Erdoğan a TelAviv após a invasão israelense da Faixa de Gaza em 2009 (idem, pp. 110-112).

Ao componente político das transformações da política externa da Turquia, agregam-se variáveis econômico-comerciais, as quais advêm das reformas estruturais por que passou o país a partir da década de 1980 . À 


\section{Mural Internacional}

época, após decênios de esforço para promover a industrialização através de uma política de substituição de importações, o governo turco lançou mão de uma profunda liberalização, com o fito de atrair investimentos externos dos países desenvolvidos. Já nos primeiros anos, alguns resultados importantes começaram a aparecer, com a chegada maciça de multinacionais interessadas na expansão do parque industrial turco. Esse processo fez com que a Turquia se tornasse um grande exportador de produtos manufaturados, aumentando sua participação no comércio internacional. Entretanto, sua economia é carente em recursos energéticos, passando a depender cada vez mais da importação de petróleo e gás. Assim, uma vez que a maior parte de seus vizinhos exporta suas riquezas naturais e importa manufaturados, desenhou-se uma situação de complementaridade econômica entre Ancara e muitos Estados lindeiros (Barkey 2012, p. 04-06).

\section{O Governo Lula e a "tradição diplomática brasileira"}

No mesmo ano em que os turcos elegeram o AKP, os brasileiros decidiram que seu futuro presidente seria Luís Inácio Lula da Silva, liderança do Partido dos Trabalhadores (PT). Por ser um partido historicamente à esquerda no espectro político, muito se indagava sobre quais seriam os rumos que a política externa brasileira tomaria, temendo-se que houvesse uma reviravolta dos principais paradigmas da diplomacia do país (Vigevani e Cepaluni, 2007). A despeito dessa apreensão - ou expectativa, em alguns casos -, Lula tratou de conservar muitos dos preceitos fundamentais que nortearam os posicionamentos brasileiros na sociedade internacional, e até mesmo algumas medidas dos últimos anos da administração anterior, quando seu antecessor, Fernando Henrique Cardoso, já demonstrava ceticismo em relação à ordem mundial e à globalização assimétrica (Silva, 2009). Contudo, o governo Lula também se pauta pela introdução de novas práticas, as quais refletem o entendimento de que o Brasil necessitava se portar de maneira mais assertiva nas questões internacionais (Amorim, 2010).

É fundamental realçar que, ao contrário do que foi reiteradamente veiculado na grande imprensa brasileira, a Declaração de Teerã não se tratou de uma ação ideológica da diplomacia do país, motivada pelas supostas pretensões irrealistas do presidente Lula. Na realidade, conforme enfatiza Amado Cervo (2008), há uma série de tradições da política externa brasileira que perpassam governos dos mais diferentes matizes ideológicos. Na visão do autor, a autodeterminação dos povos e a não intervenção externa, bem como a resolução pacífica das disputas internacionais e a ação externa cooperativa e não confrontacionista são alicerces da estratégia de inserção que o país adota. Todos esses fundamentos vão de encontro à adoção de uma postura agressiva e excludente em relação ao Irã, a qual vinha sendo defendida pelos Estados Unidos e seus aliados. Na perspectiva brasileira, essa atitude de intransigência não só seria incapaz de pavimentar um acordo futuro como ainda alijaria ainda mais os iranianos da comunidade internacional, o que poderia, paradoxalmente, deixá-los mais próximos da obtenção de uma bomba nuclear (Amorim, 2010).

A partir de tudo que foi exposto, não é difícil entender a razão pela qual não é correto afirmar que a política brasileira em relação a Teerã seja somente o fruto das particularidades do presidente Lula. No entanto, é justo que se recorde que, embora esteja claro que os elementos estruturais da diplomacia brasileira a façam se opor às 
sanções internacionais ao Irã, não há evidências que mostrem que o Brasil teria tomado a iniciativa durante a Declaração de Teerã se o contexto fosse outro. Dito de outro modo, ainda que se veja que os cânones de política externa indiquem que o Brasil seria reticente à imposição de novas sanções ao país dos aiatolás, não se concluí, daí, que o governo brasileiro procuraria exercer um papel proeminente para fazer valer seus interesses. De fato, em momentos anteriores, Brasília já mostrara sua rejeição a medidas desse tipo, mas nem por isso se engajou para evitar a aplicação de punições. Em 2010, além de fatores estruturais, percebe-se uma nítida tentativa de uma conduta mais protagônica, essa sim precípua à administração de Lula (Amorim, 2010).

De acordo com Vigevani e Cepaluni (2007), que remetem ao trabalho de Fonseca Júnior (1998), a política externa brasileira teria sofrido alguns ajustes após a posse de Lula, ainda que suas metas e objetivos principais tenham permanecido os mesmos. Em seu entendimento, até o governo Collor o país adotava uma estratégia de "autonomia pela distância", procurando se manter afastado das instituições internacionais sob a justificativa de que feriam suas aspirações. Posteriormente, já na década de 1990, Brasília incorporou a ideia da "autonomia pela participação", rompendo com o paradigma anterior, alegando que precisava participar dos fóruns internacionais para alterar as regras do jogo. Em seguida, com Lula, prevaleceria a "autonomia pela diversificação", a superação das concepções anteriores. Nesse momento o Brasil continuaria a buscar as reformas das organizações internacionais, mas através de uma diversificação de suas parcerias, para expandir sua projeção de poder. Essa diversificação não diria respeito apenas à quantidade de países com os quais deveria ter relações ativas, mas também à

\section{INTERNACIONAL}

ampliação dos temas, mesmo que não fossem os interesses considerados tradicionais.

Ao conceito de "autonomia pela diversificação" (Vigevani e Cepaluni, 2007), que já dá indícios das razões pelas quais o Brasil decidiu se envolver na crise nuclear iraniana, deve-se acrescentar o peso que o multilateralismo teve para o Estado ao longo desse governo. Com efeito, a prática de utilizar mecanismos multilaterais para a conquista de vitórias diplomáticas foi habitual durante vários governos, mas durante o mandato de Lula houve algumas modificações significativas. Pela primeira vez houve um reforço de coalizões internacionais com objetivos específicos, a fim de robustecer seu prestígio internacional, de forma a aumentar seu poder de barganha. Não pode escapar à análise, ademais, o grande esforço despendido por Lula para viabilizar a ampliação das parcerias Sul-Sul, contrastando amplamente com seus antecessores. A América do Sul - e ênfase no processo de integração regional, que foi aprofundado em vários pontos -, por exemplo, permaneceu como vetor principal da política externa brasileira. Além disso, África, Ásia e Oriente Médio adquiriram relevância inédita: após alguns anos só mirando o Norte, o Brasil voltou a dar atenção aos emergentes (Visentini e Silva 2010, p. 71).

A defesa da reforma das instituições internacionais - as quais já não representariam a atual correlação de forças da política mundial - balizou muitas das iniciativas brasileiras nos últimos anos (Lima, 2005). Conforme Celso Amorim (2010), o país sempre fez questão de frisar sua tradição diplomática pacífica, com o fito de demonstrar, a todo mundo, que estava pronto para estender suas prerrogativas enquanto player global. Assim, a luta pela expansão do Conselho de 
Segurança das Nações Unidas (CSNU) foi frequentemente $\mathrm{o}$ mote de discursos oficiais, nos quais o Brasil engrandecia suas virtudes para comprovar que deveria ser um membro permanente desse órgão. Naturalmente, como o país tinha significativas pretensões a seu respeito, não podia manter relações ativas apenas com Estados importantes em sua balança comercial. Na ótica do embaixador, uma grande potência tem o dever de estar presente no mundo inteiro, mesmo em lugares que não tenham uma dimensão destacada.

\section{Pontos de contato e convergência entre Brasil e Turquia na crise iraniana:}

Consoante ao que foi exposto até agora, vêse que houve consideráveis transformações na política externa de Brasil e Turquia a partir dos governos Lula e Erdoğan, respectivamente. Não obstante, esse movimento, embora condição sine qua non para as negociações da Declaração de Teerã, não atesta todas as motivações que fizeram com que brasileiros e turcos se comprometessem com esse tema, pois as políticas de governo podem ser consideradas como eventos situacionais, os quais seguem uma linha de tempo média. Portanto, para que possamos compreender o caminho até a Declaração de Teerã, é imprescindível que se faça, também, uma análise sobre os elementos estruturais e conjunturais que a tornaram uma realidade. Desse modo, julgamos que Brasília e Ancara se consideram potências regionais que têm capacidade para resolver, pacífica e diplomaticamente, conflitos internacionais (causas estruturais). Enfim, atenta-se que ambos procuraram se acercar comercialmente de Teerã, assim como têm programas nucleares com fim pacífico (causas conjunturais).
Neste trabalho lançamos mão dos conceitos de potência regional e potência média adotados por Nolte (2010). Para o pesquisador, o termo "potência regional" relaciona um conceito geográfico (regional) com uma noção das Relações Internacionais (potência). No entanto, o autor ressalta a pluralidade de abordagens e explicações, inviabilizando a existência de um consenso sobre o tema. Ainda assim, há concordância em relação ao fato de que as potências regionais são Estados muito influentes em seu entorno territorial, capazes de impedir uma coalizão de outros países em sua região. Já as potências intermediárias seriam, tradicionalmente, os atores com uma capacidade de pequenas alterações no sistema internacional. Atualmente, porém, considera-se como potência média o país que já não se contentava com o papel de potência regional. Desse modo, como será doravante avaliado, caberia ao Brasil e à Turquia o status de potência intermediária e de potência regional, respectivamente.

A compreensão segundo a qual Brasil e Turquia são, pelo menos, potências regionais está, atualmente, arraigada nesses países (Flemes, 2010; Bank e Karadag, 2012). A visão de que esses Estados reúnem as capacidades necessárias para que desempenhem uma função de liderança em suas regiões é hegemônica nos círculos governamentais, ainda que, naturalmente, não seja consensual. É possível se objetar porém, que houve vários momentos ao longo de sua história em que brasileiros e turcos tiveram um papel coadjuvante nas relações internacionais - o que vale, principalmente, para Ancara -, mas isso já não constitui mais a realidade. É concebível, também, encontrar argumentos que demonstrem que ainda persistem obstáculos para que essas nações possam ser consideradas como potências regionais, a começar pela resistência que seus vizinhos têm para aceitar sua liderança 
(Nolte, 2010; Malamud, 2011; Flemes, 2010).

No caso brasileiro, a posição de potência regional se tornou pouco em comparação com as pretensões do país (Guimarães, 2005). Na interpretação de Flemes (2010), Brasília já poderia ser considerada como uma potência intermediária, aqui entendida como um Estado que, mesmo que não tenha meios para, sozinho, agir efetivamente no sistema internacional, pode ter influência sistêmica se atuar em grupo ou através de uma instituição global. Com efeito, essa explicação parece se enquadrar perfeitamente na descrição das características básicas da política externa brasileira durante o governo Lula: a utilização do multilateralismo como exercício de projeção de poder é um apanágio das potências médias. $\mathrm{O}$ autor faz a ressalva, todavia, que esse multilateralismo serve para a manutenção de uma ordem global estável e ordenada e não para que se proponha a implementação de uma nova, mais justa. Dessa maneira, levando-se em consideração o caráter normativo do projeto brasileiro, que visa à criação de uma nova ordem global, Flemes questiona se o seu maior objetivo não seria, na verdade, a obtenção do status de grande potência.

Essa alegada insatisfação com a condição de potência intermediária - identificada a partir do desejo de transformações agudas na comunidade internacional - contrasta com as fragilidades estruturais que atravancam a assertividade da política externa brasileira, tornando difícil a superação do status de potência intermediária. Ainda que o país disponha de uma população significativa, de um território vasto e de pujança econômica, sua capacidade militar é diminuta. Todos os esforços que vêm sendo empreendidos para que haja uma expansão do poderio brasileiro em termos de soft power é contrabalanceado por sua tíbia política de defesa (Flemes 2010, pp. 407 - 408). Há, de fato, um descompasso entre a imagem que o Brasil tem de si mesmo e a percepção dos outros. Durante a Declaração de Teerã, todos esses fatores ficaram evidenciados, na medida em que o governo Lula tratou de se envolver em um tema relacionado a um país que tinha pouca saliência para a diplomacia brasileira, alegando que essa era uma oportunidade para demonstrar seu prestígio. Mais do que isso, era o ensejo para ter sucesso onde as grandes potências haviam falhado, o que avigoraria a ideia de que o país tinha tudo para ser mais do que sempre fora.

A situação turca não é idêntica à brasileira, mas é capital para que se compreendam as negociações com o Irã em 2010. Na segunda seção do artigo, vimos que a Turquia adotou, durante muito tempo, uma estratégia passiva, alinhada aos interesses de Washington e muito discreta em termos regionais. Observa-se, dessa maneira, que a "Teoria da Profundidade Estratégica" propugnava profundas alterações na política externa turca, com poucos paralelos em sua história. Davutoğlu acreditava que seu país não deveria ser subordinado ao Ocidente, mas sim uma potência regional autônoma e influente com todos os seus vizinhos, o que não acontecia desde o fim do Império Otomano. O governo Lula, porém, não propôs uma virada tão original, ancorando suas premissas em pressupostos clássicos da diplomacia brasileira somados a ajustes pontuais decorrentes de suas peculiaridades enquanto estadista. Como a Turquia tinha uma tradição muito mais subserviente, o programa do AKP era mais inovador do que o do PT, mas tinha obstáculos maiores para pavimentar o caminho de uma estratégia mais independente.

As pretensões turcas são consideravelmente menores do que as brasileiras, uma vez que o país só agora vem se firmando como uma 
potência regional, e não aparenta, até o momento, buscar um status de potência global. Esse comportamento é compreensível quando se recorda que os turcos, há pouco tempo, ainda eram vistos como proxy dos interesses ocidentais no Oriente Médio. Seria difícil de esperar que a Turquia abandonasse essa condição subalterna para se alçar, imediatamente, à condição de potência global, até porque suas dimensões territorial e populacional não são representativas, e sua economia não é uma das dez maiores do mundo. Para exemplificar essa diferença entre Brasília e Ancara, salta aos olhos o contraste que existe entre suas respectivas propostas para a reformulação do Conselho de Segurança da ONU. Enquanto que os brasileiros buscam uma vaga permanente nesse órgão, os turcos advogam a moção do "Unidos pelo Consenso", que sugere vagas rotativas para um país de cada região. A Turquia, nesse caso, representaria o Oriente Médio, o que revela o teor regionalista de sua política externa (Sabah, 2012).

É primordial asseverar, portanto, que há um fenômeno estrutural comum a Brasil e Turquia: sua autopercepção enquanto potências atingiu, em nossa concepção, um patamar histórico nos últimos anos. Contudo, enquanto o governo turco via seu país, pela primeira vez, como uma potência regional, o brasileiro já procurava ir além ao status de potência regional. Brasília e Ancara nunca teriam se reunido em 2010 para solucionar a crise iraniana se esse processo comum não tivesse acontecido, mas seus objetivos tinham uma natureza distinta. O AKP ambicionava a resolução de um conflito regional, de forma a materializar um dos princípios básicos da "Teoria da Profundidade Estratégica". O governo Lula, por outro lado, procedeu com o fito de expandir sua influência no sistema internacional. Em maio de 2010, Lula estava prestes a deixar o poder, e se valeu da Declaração de Teerã como última cartada para assegurar um assento permanente ao Brasil no CSNU (Jesus 2011, p. 64).

Da mesma forma que a autopercepção enquanto potência regional e média, a defesa da resolução pacífica e diplomática dos conflitos internacionais é outro aspecto estrutural compartilhado por brasileiros e turcos. Se, por um lado, pudemos verificar anteriormente que esse comprometimento já se tornou clássico para a diplomacia brasileira, configurando um importante elemento do "acumulado histórico", também é imperativo ressaltar que a Turquia tem, cada vez mais, se apegado a essa ideia, sobretudo em questões regionais. Como o país baliza sua política externa na tática de evitar problemas com seus vizinhos, é de seu entendimento que é necessário assegurar a estabilidade desses Estados, na medida em que qualquer turbulência poderia engendrar hostilidades que lhe atinjam. Por conseguinte, Ancara considera que o alijamento iraniano e as novas sanções econômicas só o deixariam ainda mais instável, inviabilizando a construção de uma ordem regional minimamente harmônica (Üstün 2010, pp. 21-22).

Brasil e Turquia não articularam a Declaração de Teerã apenas por razões estruturais e situacionais. Com efeito, os fenômenos conjunturais também parecem ter sido muito pertinentes para essa aproximação. A esse respeito, sublinha-se que não tratamos como conjunturais apenas os acontecimentos mais recentes, mas sim os fatores cuja capacidade de reverberação é de curto prazo, visto que estão menos enraizados na diplomacia do país, o que faz com que sejam mais facilmente reversíveis. Nessa linha, os programas turco e brasileiro para o desenvolvimento de energia nuclear e a tentativa que esses países empreenderam para se acercar econômica e comercialmente do Irã preenchem esses 
pré-requisitos. Afinal, vê-se que a utilização da energia nuclear não é vital para a economia desses países, uma vez que preenchem uma mínima parcela de sua matriz energética. $\mathrm{O}$ Brasil se vale majoritariamente de seus recursos hídricos, ao passo que a Turquia, carente em energia, importa petróleo e gás de seus vizinhos para manter sua economia em funcionamento.

Do mesmo modo, os fatores econômicocomerciais também podem ser apontados como causas conjunturais para a iniciativa turco-brasileira. Para Ancara, um estreitamento de laços com Teerã seria de fundamental importância, dada a complementaridade econômica entre os países. Afinal, se os iranianos se mostram extremamente dependentes da exportação de petróleo, vemos que os turcos necessitam de energia e de mercados para vender seus produtos manufaturados (Larrabee e Nader 2013, pp. 31-32). Já o Brasil, conquanto seja praticamente autossuficiente em petróleo, também viu uma oportunidade única para estabelecer negócios com o Irã, na medida em que o isolamento a que o país estava submetido abria um imenso campo de possibilidades de investimentos em seu setor petrolífero. Ademais, setores como construção civil e indústria naval também poderiam atrair empresários brasileiros. Por fim, a pujança da agricultura brasileira seria outro atrativo, dada a dificuldade de produzir alimentos em solo iraniano (Pinto, 2012).

A despeito das limitações das razões conjunturais, não acreditamos que sua expressão seja pequena, uma vez que são costumeiras as situações em que fatores desse tipo são a razão última para a tomada de decisões. Por mais que a energia nuclear não seja crucial para Ancara e Brasília, os governos do AKP e do PT não abrem mão desse direito, como atesta sua vontade de construir plantas para a produção energética a partir de urânio. No Brasil, os reatores nucleares entraram em funcionamento em 1984, com a usina de Angra I - fruto do Acordo Nuclear Brasil-Alemanha. $\mathrm{Na}$ sequência, em 2001, Angra II teve sua operação comercial iniciada. Em 2010, o governo brasileiro retomou as obras de Angra III, que deve ser inaugurada em 2016 (O Globo, 2011). A Turquia, por seu turno, ainda não tem usinas nucleares, mas o $\mathrm{AKP}$ já anunciou que pretende construir três nos próximos anos, através de um acordo de cooperação com a Rússia e com o Japão. Naturalmente, quando Lula e Erdoğan reiteraram que o Irã tem direito ao uso pacífico de energia nuclear, havia uma mensagem implícita de que seus próprios projetos eram legítimos (Gürzel 2012, pp. 143-144).

Ainda no que diz respeito à defesa brasileira do programa nuclear iraniano, para além de questões objetivas e conjunturais (o desejo de diversificar as fontes energéticas e de qualificar o país em termos tecnológicos), também podemos observar a presença de aspectos estruturais e situacionais. Por um lado, aqueles se manifestam na já atávica crítica brasileira ao congelamento do poder mundial, na medida em que as grandes potências procuram cristalizar o sistema internacional com poucos países que possuem armamentos nucleares e o resto à sua mercê (Patti 2010, p. 178). Já esses se verificam na rechaça do governo Lula em assinar o Protocolo Adicional do TNP: para o Executivo brasileiro, essa medida comprometeria a soberania e a segurança nacional, pois poderia prejudicar os interesses brasileiros no desenvolvimento da tecnologia de centrifugação e nos aspectos comerciais a esta relacionados. Vale salientar que a posição brasileira é um alívio para Teerã, que tampouco é signatário do Protocolo Adicional (Jesus 2011a, p. 111-112). 
Apesar da rejeição internacional à qual está submetido o Irã - agravada a partir da eleição do conservador Mahmud Ahmadinejad em 2005 -, Turquia e Brasil sempre enxergaram com bons olhos um acercamento com o Estado persa. Como averiguado acima, Ancara é carente em recursos energéticos, mas exporta produtos manufaturados em abundância, gerando uma situação de complementaridade econômica com Teerã. Ademais, os empresários turcos se mostram ávidos para estender seus investimentos nos setores petrolífero e de construção civil do Irã, os quais se encontram subaproveitados em decorrência das sanções internacionais (Gürzel 2012, pp. 145-147). Brasília também se beneficiaria enormemente de uma parceria comercial com os iranianos, já que esses representaram, até 2011, o quinto principal comprador do seu agronegócio. O território iraniano não é adequado à produção de alimentos, o que daria enormes oportunidades à agricultura brasileira. Além disso, 99,9\% do comércio entre os dois países se compunha de exportações brasileiras, o maior superávit comercial do país. Por fim, o Irã seria um excelente mercado para os setores de aviação civil, construção naval e mineração, beneficiando inúmeras empresas brasileiras (Pinto, 2012).

\section{Considerações finais}

Nosso objetivo ao longo do texto foi evidenciar os fatores que determinaram a convergência turco-brasileira em maio de 2010, quando esses países chegaram a um acordo com o Irã para resolver o impasse envolvendo seu programa nuclear. Através de uma análise que procurou levar em consideração os fatores estruturais, situacionais e conjunturais que formam os principais condicionantes da política externa turca e brasileira, demonstramos que foram vários os pontos de convergência entre Brasília e Ancara que ensejaram a Declaração de Teerã. É forçoso reconhecer, porém, que fenômenos à primeira vista idênticos frequentemente assumem uma dimensão distinta de acordo com as circunstâncias, podendo ser considerados estruturais para uns, mas situacionais ou conjunturais para outros. De modo semelhante, ainda que normalmente os países cooperem porque compartilham razões para tal, motivações distintas também podem ocasionar uma aproximação.

A autopercepção de Turquia e Brasil enquanto potências (pelo menos em nível regional) foi o primeiro fator estrutural que destacamos como causa para o acordo. Embora os brasileiros tenham pretensões maiores - uma vez que até a categoria de potência média lhes parece pouco, ao passo que os turcos se contentam em ser uma potência regional -, ambos se enxergam como Estados que devem participar das negociações das crises internacionais. No entanto, ainda que o elemento estrutural seja o mesmo (a autopercepção de que são potências), há uma diferença: o governo brasileiro só se interessou pelo Irã porque tem aspirações globais, dada a exígua relevância do Irã para sua diplomacia, mas o AKP empenhou-se para achar a resposta para uma crise regional, em sua própria esfera de influência. Caso esse conflito envolvesse um país sul-americano, não seria provável a presença da Turquia, visto que seus anseios vão pouco além de sua região. Além do mais, Ancara e Brasília partilham da crença de que os litígios internacionais precisam ser sanados sem o recurso à força ou a sanções, outro componente estrutural.

Em termos situacionais, vimos que a emergência do AKP, na Turquia, e do PT, no Brasil, suscitaram transformações para a política externa desses países. Desde que 


\section{Mural Internacional}

assumiram o poder, esses governos buscaram maior autonomia em relação às grandes potências. Realçamos, também, que as mudanças capitaneadas por Erdoğan foram mais acentuadas, enquanto que Lula lançou mão de preceitos consagrados da política externa brasileira (como a defesa da pesquisa nuclear para fins pacíficos) para nortear suas ações, além das alterações decorrentes de seus traços pessoais, naturalmente. Por último, traçamos uma avaliação dos pretextos conjunturais que moldaram a atuação desses Estados diante da Declaração de Teerã, dentre as quais destacam a argumentação favorável ao uso da energia nuclear com fins pacíficos - o Brasil já tem usinas nucleares há bastante tempo, e a Turquia tem projetos para construir três - e o interesse no estreitamento de laços econômicos com o Irã, uma vez que ambos têm uma grande produção de artigos muito requisitados no país dos aiatolás (Pinto, 2012; Gürzel, 2012).

Malgrado a vasta convergência entre Ancara e Brasília para formalizar a
Declaração de Teerã, é muito oportuno notabilizar os contrastes que também ditaram o rumo dos acontecimentos. Como asseveramos, há um conjunto de fenômenos estruturais, situacionais e conjunturais que confluíram, nos dois países, para que estes trabalhassem em prol da solução da crise nuclear iraniana. Em última instância, porém, a motivação final para que os governos turco e brasileiro tentassem obter êxito após o fracasso das grandes potências se deu por razões distintas. Por um lado, constatamos que Lula deu relevo à situação iraniana porque acreditava que essa seria a derradeira oportunidade de sua administração para que o Brasil mostrasse suas virtudes enquanto negociador, atestando sua magnitude para a política internacional, o que entendemos como causa conjuntural. Erdoğan, ao contrário, pretendia colocar em prática o projeto político de seu partido, o qual preza pela concórdia regional, sem demonstrar interesse em uma projeção global.

\section{Referências bibliográficas:}

Amorim, C. (2010). Brazilian Foreign Policy under President Lula (2003-2010): an overview, Revista Brasileira de Política Internacional, 53, Special, pp.214-240.

Balci, A. \& Kardaş, T. (2012) The Changing Dynamics of Turkey’s Relations with Israel: An Analysis of "Securization", Insight Turkey, 14(2), pp.99-120.

Bank, A. \& Karadag, R. (2012). 'The Political Economy of Regional Power: Turkey under the AKP'. German Institute of Global and Area Studies, 204, pp.01-24.

Baran, Z. et alli (2008). 'Turkey's Identity and Strategy: A Game of Tri-Dimensional Chess'. Power and Principles: International Leadership in a Shrinking World, pp.01-23.

Barkey, H. (2012). 'The Evolution of Turkish Foreign Policy in the Middle East'. TESEV Foreign Policy Program, pp.01-08.

Cervo, A. (2008). Inserção Internacional: Formação dos conceitos brasileiros. São Paulo: Saraiva. 
Dicle, B. (2008). Factors Driving Turkish Foreign Policy.

Flemes, D. (2010). 'O Brasil na Iniciativa BRIC: Soft Balancing numa Ordem Global em Mudança?', Revista Brasileira de Política Internacional, 53(1), pp.141-156.

Fonseca, Jr., G. (1998). A Legitimidade e Outras Questões Internacionais. São Paulo: Paz e Terra.

Fonteijn, M.; Assl, N. \& Ingram, P. (2010). New Players in the Dispute over Iran's Nuclear Program, British American Security Information Council, pp.02-11.

Guimarães, S. P. (2005). Desafios brasileiros na era de gigantes. Rio de Janeiro: Contraponto.

O Globo. 'Até 2021, Apenas Angra III Sairá do Papel'. Disponível em: http://oglobo.globo.com/economia/ate-2021-apenas-angra-3-saira-do-papel-2761245 Acessado em 29 de nov. 2013.

Gürzel, A. (2012). 'Turkey's Role in Defusing the Iranian Nuclear Issue'. The Washington Quarterly, 35(3), pp.141-152.

Jesus, D. (2011). 'Building Trust and Flexibility: A Brazilian View of the Fuel Swap with Iran'. The Washington Quarterly, 34(2), pp.61-75.

—. (2011a). 'Desde Angra Hacia Teherán: La Política Nuclear Brasileña Bajo la Administración Lula'. América Latina Hoy, 58, pp.103-120.

Kaya, K. (2011). 'Changing Trends in Israel-Turkey Security and Military Relations: Their Perspectives'. Foreign Military Studies Office, pp.01-17.

Larrabee, F. S. \& Nader, A. (2013). 'Turkish-Iranian Relations in a Changing Middle East'. National Defense Research Institute, pp.01-46

Lima, M. R. S. (2005). 'A política externa brasileira e os desafios da cooperação Sul-Sul'. Revista Brasileira de Política Internacional, 48(1), pp.24-59.

Hirst, M.; Lima, M. R. S.; Pinheiro, L. (2010). 'A Política Externa Brasileira em Tempos de Novos Horizontes e Desafios’. Nueva Sociedad, 1, pp.22-41.

Malamud, A. (2011). 'A Leader without Followers? The Growing Divergence between the Regional and Global Performance of Brazilian Foreign Policy'. Latin American Politics and Society, 53(3), pp. 01-24.

Nolte, D. (2010). 'How to compare regional powers: analytical concepts and research topics'. British International Studies Association, Review of International Studies, 36, pp. 881-901.

Ozkan, M. (2011). 'Turkey-Brazil Involvement in Iranian Nuclear Issue: What Is the Big Deal?'. Strategic Analysis, 35(1), pp.26-30.

Parsi, T. (2012). A Single Roll of the Dice. London: Yale University Press.

Patti, C. (2010). 'Brazil and the Nuclear Issues in the Years of the Luiz Inácio Lula da Silva Government (2003-2010)'. Revista Brasileira de Política Internacional, 53(2), pp.178-195. 


\section{Mural Internacional}

Pinto, F. (2012). 'O Acerto da Política Iraniana de Lula'. Disponível em: http://www.cartacapital.com.br/internacional/o-acerto-da-politica-iraniana-de-lula/. Acessado em 27 de nov. 2013.

Saraiva, M. G. (2007). 'As estratégias de cooperação Sul-Sul nos marcos da política externa brasileira de 1993 a 2007'. Revista Brasileira de Política Internacional, 50(2), pp.42-59.

Sabah. (2012). Davutoğlu Delivers Impressive Speech at UN General Assembly, 2012. Disponível em: http://english.sabah.com.tr/national/2012/09/29/davutoglus-un-generalassembly-address Acessado em 25 de nov. 2013.

Silva, A. (2009). Do Otimismo Liberal à Globalização Assimétrica. Curitiba: Juruá.

Üstün, K. (2010). 'Turkey's Iran Policy: Between Diplomacy and Sanctions'. Insight Turkey, 12(3), pp.19-26.

Vidal, C. (2012). 'O Protagonismo Brasileiro Diante da Declaração de Teerã'. Conjuntura Austral, 4(18), pp.41-61.

Vigevani, T. \& Cepaluni, G. (2007). 'A Política Externa de Lula da Silva: A Estratégia da Autonomia pela Diversificação'. Contexto Internacional, 29(2), pp.273-335.

Visentini, P. \& Silva, A. (2010). 'Brazil and the Economic, Political, and Environmental Multilateralism: the Lula years (2003-2010)'. Revista Brasileira de Política Internacional, 53, Special, pp.54-72. 